УдК 616.33-089.819-089.12

$\mathrm{DOI}$

(С) А. Ю. УСЕНКО, Е. П. ДМИТРЕНКО

ГУ "Национальный институт хирургии и трансплантологии им. А. А. Шалимова" НАМН Украины

\title{
Особенности лапароскопической фундопликации
}

\author{
O. YU. USENKO, E. P. DMYTRENKO \\ SI "National Institute of Surgery and Transplantation by O. O. Shalimov" of NAMS of Ukraine
}

\section{FEATURES OF LAPAROSCOPIC FUNDOPLICATION}

\begin{abstract}
В исследовании представлены результаты обследования и хирургического лечения 85 больных с гастроэзофагеальной рефлюксной болезнью с сопутствующей грыжей пищеводного отверстия диафрагмы. Всем больным в плановом порядке была выполнена лапароскопическая крурорафия и фундопликация. У 3 (3,6 \%) пациентов зарегистрирован рецидив заболевания, у 1 из них через 2 года после операции, у 2 через 5 лет. У всех больных рецидив грыжи пищеводного отверстия диафрагмы (ГПОД) и гастроэзофагеальной рефлюксной болезни (ГЭРБ) наблюдался у пациентов со смешанной ГПОД. Лапароскопическая фундопликация является эффективным методом лечения больных гастроэзофагеальной рефлюксной болезнью на фоне грыжи пищеводного отверстия диафрагмы.

The study presents the results of research and surgical treatment of 85 patients with gastroesophageal reflux disease with concomitant hiatal hernia. All patients routinely underwent laparoscopic fundoplication and crurorafy. In 3 (3.6 \%) patients the recurrent disease was registered, and 1 of them 2 years after surgery, 2 in 5 years. In all patients relapse of hiatal hemia and GERD was observed in patients with of hiatal hernia of type III. Laparoscopic fundoplication is an effective method of treatment of patients with gastroesophageal reflux disease on the background of hiatal hernia.
\end{abstract}

Постановка проблемы и анализ последних исследований и публикаций. Первая в мире лапароскопическая фундопликация была выполнена относительно недавно Dallemagne и соавт. в 1991 г., которая и в настоящее время остается одной из самых распространённых методик $[1,2]$.

На сегодняшний день успешные результаты после лапароскопической фундопликации достигают в 85-95 \% [3, 4] случав, и эта операция хорошо переносится пациентами [5].

Но у 4-18 \% больных, по данным различных авторов, выполняются повторные операции в сроки наблюдения до 10 лет. Самая высокая частота повторных операций регистрируется в течение 1 года после операции (1,7 \% в год) и неуклонно уменьшается в течение следующих 4 лет, достигая 0,5 \% в год [6-8].

Анализ основных причин повторных антирефлюксных операций показал, что наиболее частыми показаниями являлись: рецидив рефлюкса (в 41,7 \% случаев), дисфагия (16,6 \%). У 4,0 \% пациентов, перенесших повторную операцию, отмечался рецидив рефлюкса в сочетании с дисфагией. В своих наблюденияй Catarci послеоперационную дисфагию наблюдал у 16,8 \% после фундопликации по Ниссену и у 9,3 \% пациентов после фундопликации по Тупе [4].
Ранее считалось, что с целью снижения частоты послеоперационной дисфагии у пациентов с нарушенной моторикой пищевода методом выбора является частичная фундопликация [9]. Однако результаты рандомизированного клинического исследования говорят о преимуществах полной “короткой” фундопликации [10]. Повышение надежности антирефлюксного механизма при фундопликации по Тупе возможно при формировании более широкой манжетки до 3 см, а снижение частоты развития дисфагии при фундопликации по Ниссену при наложении более узкой до 2 см манжетки $[11,12,13]$.

Мобилизация дна желудка с пересечением коротких сосудов, задняя круроррафия и фиксация манжетки к пищеводу позволили снизить частоту соскальзывания манжетки с 13-15 \% до 0 \% [14].

Мобилизация абдоминального отдела пищевода, свободно наложенная манжетка и выполненная крурорафия позволяют снизить неэффективность фундопликационной манжетки [15].

Развитие лапароскопических технологий позволило выполнять операции на пищеводно-желудочном переходе менее травматично, снизило сроки реабилитации и временной утраты трудоспособности пациентов. Однако, использование лапароскопических технологий в хирургии 
пищеводно-желудочного перехода не решает проблему неудовлетворительных результатов хирургического лечения и развития рецидива заболевания. Основными вопросами антирефлюксной хирургии до сих пор является соотношение между типом создаваемой манжетки, степенью мобилизации дна желудка и абдоминального отдела пищевода и частотой развития послеоперационной дисфагии. Данная проблема достаточно актуальна и требует пристального внимания, детального анализа и поиска путей ее решения.

Цель работы: анализ результатов лапароскопической фундопликации у пациентов с гастроэзофагеальной рефлюксной болезнью на фоне грыжи пищеводного отверстия диафрагмы для улучшения отдалённых результатов лечения.

Материалы и методы. В основе исследования лежат результаты обследования и хирургического лечения 85 больных с гастроэзофагеальной рефлюксной болезнью с сопутствующей грыжей пищеводного отверстия диафрагмы, которые находились на хирургическом лечении в ГУ “Национальный институт хирургии и трансплантологии им. А. А. Шалимова” НАМН Украины за период с 2005 по 2015 год. Всем больным в плановом порядке была выполнена лапароскопическая коррекция замыкательной функции нижнего пищеводного сфинктера.

В алгоритм оценки морфофункционального состояния пищевода, пищеводно-желудочного перехода было включено эндоскопическое, рентгенологическое исследование, $\mathrm{pH}$-метрия пищевода и желудка, манометрия пищевода.

При оценке состояния пищеводно-желудочного перехода обращали внимание на уровень расположения зубчатой линии, функциональное состояние нижнего пищеводного сфинктера и кардии, состояние слизистой оболочки пищевода (гиперемия, отек, наличие эрозий и язв). Особое внимание обращали на наличие и оценку очагов метаплазии слизистой оболочки пищевода (пищевод Барретта).

Женщин было 51 (60 \%), мужчин - 34 (40 \%). Чаще всего ГЭРБ встречалась в возрасте от 31 до 60 лет. Самой частой жалобой была изжога, которая отмечена у 47 (55,3 \%) больных. У 10 (11,8 \%) больных преобладали внепищеводные проявления. Средняя продолжительность заболевания составила $(45,7 \pm 11,3)$ месяца.

Более чем у половины пациентов - 46 (54,1 \%) диагностирована эндоскопически негативная форма ГЭРБ. В структуре рефлюкс-эзофагита чаще всего встречался рефлюкс-эзофагит LA-C у 38 (44,7 \%) больных, наиболее редко рефлюкс-эзофагит LA-D y 5 (5,9 \%) пациентов. Пищевод Барретта встречался у 2 (2,4 \%) больных, язва пищевода у 3 (3,5 \%) пациентов, стриктура пищевода у 2 (2,4 \%) больных. Обычно кардия находится на расстоянии 39-41 см от резцов у мужчин и 38-39 см у женщин.

По данным рентгенологического исследования, наиболее часто ГЭРБ ассоциировалась со смешанной ГПОД (СГПОД) - у 41 (48,2 \%) больного, наиболее редко с параэзофагеальной ГПОД (ПГПОД) - у 1 (1,2 \%) больного.

У 24 (28,2 \%) больных диагностирован короткий пищевод - I степени, у 17 (20,0 \%) - II степени.

У всех пациентов диагностирован патологический желудочно-пищеводный рефлюкс, и ин-

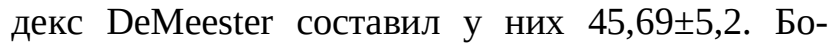
лее чем у половины пациентов - 46 (54,1 \%) зарегистрирован рефлюкс в ночное время. Следует отметить, что более чем у половины пациентов 47 (55,3 \%) базальное рН в желудке было в пределах нормы. Только у трети пациентов - 26 (30,6 \%) регистрировалась гиперацидность желудка.

Для пациентов, у которых патологический рефлюкс регистрировался в дневное время, было характерно преобладание эндоскопически негативной ГЭРБ. У пациентов с ночным и “постоянным” рефлюксом при эндоскопическом исследовании диагностировались эрозивные изменения слизистой оболочки пищевода.

Манометрия пищевода была выполнена 60 (70,6 \%) пациентам. У 5 (5,3 \%) из них давление нижнего пищеводного сфинктера находилось в пределах нормы. У остальных пациентов давление нижнего пищеводного сфинктера было значительно снижено и в среднем составляло $((0,8-1,1)$ $\pm 0,1)$ кПа $((6,25-8,44) \pm 0,97)$ мм рт. ст.

Основными техническими особенностями антирефлюксной операции были: низведение абдоминального отдела пищевода не менее 3 см в брюшную полость, формирование безнатяжной манжетки из дна желудка вокруг пищевода, использование для фиксации тканей нерассасывающийся шовный материал, выполнение крурорафии и фундопликации на толстом желудочном зонде 56-60 Fr. При полной фундопликации - мобилизация дна желудка с пересечением коротких сосудов желудка и формирование короткой манжетки до 2 см, при частичной фундопликации на $270^{\circ}$ - манжетки не менее 3 см.

При оперативной коррекции антрирефлюксного механизма мы выполняли как полную, так и частичную фундопликации. У 1 пациента была выполнена полная фундопликация в модификации Ниссен-Розетти, без пересечения желудочно- 
селезеночной связки и мобилизации дна желудка. При частичной фундопликации выполняли заднюю фундопликацию по Тупе.

Задняя крурорафия выполнена у 76 (89,4 \%) больных, у 6 (7,1 \%) из них мы использовали тефлоновые протезы, у 3 (3,5 \%) больных задняя крурорафия была дополнена передней. 1 (1,2 \%) пациенту при хиатопластике на пищеводное отверстие диафрагмы был имплантирован синтетический протез. Полная лапароскопическая фундопликация по Флоппи-Ниссену была выполнена 70 (82,4 \%) пациентам, фундопликация по Ниссену в модификации Розетти - 1 (1,2 \%) пациенту. Частичная задняя фундопликация по Тупе выполнена 14 (16,5 \%) пациентам.

Результаты исследований и их обсуждение. Средняя продолжительность операций составила $(256,9 \pm 80,3)$ мин, средняя кровопотеря $(147,8 \pm 44,9)$ мл.

В раннем послеоперационном периоде типичных жалоб, характерных для желудочно-пищеводного рефлюкса, ни у одного пациента обеих групп не было зарегистрировано. Явления дисфагии в раннем послеоперационном периоде мы наблюдали у 8 (9,4 \%) пациентов, вздутие живота у 2 (2,4 \%) больных, раннее насыщение после принятия пищи у 5 (5,9 \%) больных. К моменту выписки из клиники все эти жалобы купировались самостоятельно.

У 2 (2,4 \%) пациентов в начале освоения лапароскопической методики имело место кровотечение из коротких сосудов желудка и травматическое повреждение печени, у 3 (3,5 \%) пациентов - левосторонний пневмоторакс, в связи с чем у 2 (2,4 \%) из них потребовалась конверсия. Повреждение пищевода и осложнения гнойносептического характера ни у одного пациента мы не наблюдали. Послеоперационный койко-день $(4,00 \pm 2,03)$ дня.

В течение первого года у 4 (4,7 \%) пациентов наблюдались дисфагия, вздутие живота, интен-

\section{СПИСОК ЛИТЕРАТУРЫ}

1. Salminen P. T. P. Comparison of long-term outcome of laparoscopic and conventional nissen fundoplication: a prospective randomized study with an 11-year follow-up / P. T. P. Salminen, H. I. Hiekkanen // Ann. Surg. - 2007. - Vol. 246, № 2. - P. 201216.

2. Sharp N. E. Single-site nissen fundoplication versus laparoscopic nissen fundoplication / N. E. Sharp, J. Vassaur, F. P. Buckley // JSLS. - 2014. - Vol. 18.

3. 20 years later: laparoscopic fundoplication durability / B. Robinson, C. M. Dunst, M. A. Cassera [et al.] // Surg. Endosc. - 2014. Epub ahead of print. сивность проявлений которых со временем уменьшилась. В течение первого полугода эти жалобы имели место у 3 (3,5 \%) больных. В сроки до 2 лет данных о рецидиве ГЭРБ ни у одного пациента мы ни клинически, ни инструментально не зарегистрировали.

Через 2 года рецидив ГЭРБ был зарегистрирован у 1 (1,2 \%) больного. При ЭФГДС диагностирован пищевод Барретта на фоне возобновления типичной симптоматики.

Через 5 лет и более после оперативного вмешательства у 2 (2,4 \%) больных диагностирован рецидив ГПОД с возобновлением симптоматики ГЭРБ. Больные вернулись к приему медикаментозной терапии по причине рецидива заболевания. Несмотря на рецидив ГЭРБ качество жизни этих пациентов было выше, чем до операции, и в целом пациенты были удовлетворены результатами лечения.

У всех больных рецидив ГПОД и ГЭРБ наблюдался у пациентов со смешенной ГПОД. Ни у одного пациента с использованием тефлоновых протезов рецидива заболевания мы не отмечали.

Выводы. Лапароскопические антирефлюксные оперативные вмешательства у пациентов с гастроэзофагеальной рефлюксной болезнью позволяют получить хорошие и удовлетворительные результаты у 97 \% больных. Лапароскопическая фундопликация является эффективным методом лечения больных гастроэзофагеальной рефлюксной болезнью на фоне грыжи пищеводного отверстия диафрагмы и позволяет нормализовать индекс DeMeester, повысить давление НПС и нормализовать состояние слизистой пищеводножелудочного перехода.

Перспективы дальнейших исследований. Разработка и модификация имеющихся вмешательств с целью улучшения результатов оперативного вмешательства являются перспективным направлением современной хирургии.

4. Laparoscopic fundoplication: Nissen versus Toupet two-year outcome of a prospective randomized study of 200 patients regarding preoperative esophageal motility / U. Strate, A. Emmermann, C. Fibbe [et al.] // Surg. Endosc. - 2008. - Vol. 22, № 1. - P. 21-30.

5. Qu H. Short- and long-term results of laparoscopic versus open anti-reflux surgery: a systematic review and meta-analysis of randomized controlled trials / H. Qu, Y. Liu, Q. S. He // J. Gastrointest. Surg. - 2014. - Vol. 18, № 6. - P. 1077-1086. doi: 10.1007/s11605-014-2492-6. Epub 2014 Mar 14.

6. Gooszen Surgical ReinterventionAfter Failed Antireflux 


\section{З ДОСВІДУ РОБОТИ}

Surgery: A Systematic Review of the Literature / E. J. B. Furnee, W. A. Draaisma, L. A. Breeders, G. Hein // J. Gastrointest. Surg. - 2009. - Vol. 13, 8. - P. 1539-1549.

7. Neuvonen P. Endoscopic evaluation of laparoscopic nissen fundoplication: $89 \%$ success rate 10 years after surgery / P. Neuvonen, M. Iivonen, T. Rantanen // World J. Surg. - 2014. Vol. 38, № 4. - P. 882-889. doi: 10.1007/s00268-013-2349-2.

8. A meta-analysis comparing laparoscopic partial versus Nissen fundoplication / S. Ma, B. Qian, L. Shang [et al.] // ANZ J. Surg. - 2012. - Vol. 82, № 1-2. - P. 17-22. doi: 10.1111/j.14452197.2010.05637.x. Epub 2011 Jan 20.

9. Randomized clinical trial of laparoscopic total (Nissen) versus posterior partial (Toupet) fundoplication for gastro-oesophageal reflux disease based on preoperative oesophageal manometry / M. I. Booth, J. Stratford, L. Jones, T. C. Dehn // Br. J. Surg. - 2008. - Vol. 95. - P. 57-63.

10. Hunter J. G. Dysphagia after laparoscopic antireflux surgery: the impact of operative technique / J. G. Hunter, L. Swanstrom, J. P. Waring // Ann. Surg. - 1996. - Vol. 224, № 1. - P. 51-57.

11. Proton pump inhibitor treatment of patients with gastroesophageal reflux-related chronic cough: a comparison between two dif- ferent daily doses of lansoprazole / F. Baldi, R. Cappiello, C. Cavoli [et al.] // World J. Gastroenterol. - 2006. - Vol. 12. - P. 82-88.

12. Comparison of long-term outcome of laparoscopic and conventional nissen fundoplication: a prospective randomized study with an 11-year follow-up / P. T. Salminen, H. I. Hiekkanen, A. P. Rantala, J. T. Ovaska // Ann. Surg. - 2007. - Vol. 246, № 2. - P. 201-206.

13. Five-year subjective and objective results of laparoscopic and conventional Nissen fundoplication: a randomized trial / W. A. Draaisma, H. G. Rijnhart-de Jong, L. A. Breeders [et al.] // Ann. Surg. - 2006. - Vol. 244. - P. 34-41.

14. Failed antireflux surgery: quality of life and surgical outcome after laparscopicrefun-doplication / F. A. Granderath, F. Kamolz, U. M. Schweiger [et al.] // Int. J. Colorectal. Dis. - 2003. Vol. 18. - P. 248-253.

15. 139 A randomized, double-blind trial of the efficacy and safety of 10 or $20 \mathrm{mg}$ rabeprazole compared with $20 \mathrm{mg}$ omeprazole in the maintenance of gastro-oesophageal reflux disease over 5 years / B. Thjodleifsson, G. Rindi, R. Fiocca [et al.] and European Rabeprazole Study Group // Aliment. Pharmacol. Ther. - 2003. Vol. 17, № 3. - P. 343-351. 


\title{
Аналіз операційних втручань при пошкодженнях ротаціӥної манжети плеча із застосуванням артроскопії
}

\author{
IU. M. PIVEN, I. V. KSONZ, IU. P. LYTVYN, O. V. PELYPENKO ${ }^{1}$, S. M. PAVLENKO
}

Higher State Educational Institution of Ukraine "Ukrainian Medical Stomatological Academy", Poltava State Institution "Dnipropetrovsk Medical Academy"

\section{ANALYSIS OF OPERATIVE INTERVENTIONS AT DAMAGES OF ROTATOR GUFF OF SHOULDER USING THE ARTHROSCOPY}

\begin{abstract}
У статті наведено результати лікування пошкоджень ротаційної манжети плеча у 72 хворих при використанні як малоінвазивної відкритої методики (61 пацієнт), так і при артроскопії (11 пацієнтів). Проведений аналіз показав: більше половини пацієнтів мали внутрішньосуглобові патології, поєднані 3 пошкодженням ротаційної манжети плеча; найбільш оптимальним початком операційного втручання є артроскопія, яка дозволяє діагностувати всі пошкодження плечового суглоба, а по можливості їх усунути. Малоінвазивне відкрите виправдане при тотальних розривах з відривом від місця інсеції ротаційної манжети плеча і в застарілих випадках при вираженій рефракції сухожильних частин.

The article adduces the results of treatment of damages of rotary cuff of shoulder, in 72 patients using of both little invasive open methodology (61 patients) and arthroscopy (11 patients). The conducted analysis showed: the more than half of patients had intra-articular pathologies combination with the damage of rotary cuff of shoulder; most optimal beginning of operative intervention from arthroscopy that allows to diagnose all damages of humeral joint, and at possibility and their removals. Little invasive open interference is justified at total breaks, with tearing away from the place of insertion of rotator cuff of shoulder and in inveterate cases at the expressed retraction of tendon parts.
\end{abstract}

Постановка проблеми і аналіз останніх досліджень та публікацій. Мобільність та міцність сухожильно-капсульного апаратаплечовогосуглоба, в склад якого входить ротаційна манжета плеча (РМП), є основою оптимального функціонування верхньої кінцівки [5]. Діапазон рухів, що виконується верхньою кінцівкою в плечовому суглобi, $\in$ в від надзвичайно різко напруженого (наприклад, підняття ваги над головою), до надзвичайно точного (наприклад, кидання дротика при грі в дартс). Продуктивна життєздатність людини залежить від повного безболісного об’єму рухів у плечовому суглобі.

Успіх лікування пацієнтів із пошкодженнями РМП являє собою проблему для лікарів у виборі методу лікування. Більшість, особливо в умовах поліклінічних відділень або в районних лікарнях, віддають перевагу консервативному лікуванню, в кращому випадку відкритому відновленню цілісності та реінсерції РМП, забуваючи при цьому про багатогранність даного типу ушкодження, підводячи все під один діагноз “розрив сухожилків”. Точна діагностика ушкодження структур плечового суглоба, функціональні вимоги хворого до кінцівки - все це є основними критеріями для досягнення найкращого результату лікуван- ня. Крім того, технічні навички, знання анатомічних особливостей плечового суглоба, а також розуміння в потребі відновлення при пошкодженні РМП потребують хірургічного досвіду, що далеко не кожен ортопед-травматолог може показати при лікуванні таких хворих.

В останнє десятиліття значно збільшилась кількість хворих із пошкодженням сухожильнокапсульного апарата плечового суглоба $[1,6,7]$. На нашу думку, це вписується в основні дві концепції (травматичну та диспластичну), що призводять до даного типу уражень [3], оскільки суспільство можна умовно поділити на дві групи. Першу, в якій люди ведуть так званий “здоровий спосіб життя”: починають займатись фітнесом, різними видами спорту, i, як наслідок, у більшості випадків виникає (аналіз причин отримання травми при зверненні хворого) некероване перевантаження сухожильно-капсульного апарата плечового суглоба (травматична концепція). Другу, в якій все кардинальнопротилежне: надмірна маса пацієнтів, зловживання алкоголем, куріння, що призводить, особливо у віці після 40 років, до дегенеративнодистрофічних змін сухожилків, і, як наслідок, незначна травма призводить до їх ушкодження (диспластична концепція). 
Велика кількість досліджень [1, 2, 3, 6, 7] з приводу такого типу пошкоджень все ще не дає чіткої відповіді у первинному виборі операційного втручання: артроскопічного чи відкритого малоінвазивного, а їх результати, незважаючи на значний науково-технічний прогрес у галузі медицини, залишаються ще далекими від ідеальних у функціональному відновленні верхньої кінцівки та боротьбі із больовим синдромом.

Все це, в свою чергу, впливає на працездатність пацієнта, порушує його сон, знижує якість життя хворого, а також виключає його як повноцінного працівника суспільства.

Отже, потрібен пошук комплесу пошкоджень сухожильно-капсульного апарата плечового суглоба, а, виходячи з цього, і вибір правильного методу лікування.

Мета роботи: покращити результати лікування, зокрема відновити функціональність верхньої кінцівки, об'єм рухів у плечовому суглобі, зменшити розвиток посттравматичного артрозу, зменшити строки непрацездатності, знизити відсоток виходу на інвалідність хворих шляхом розробки системи комплексного лікування, що базується на правильній діагностиці пошкоджень сухожильнокапсульного апарата плечового суглоба і виборі адекватної тактики лікування із розумінням анатомічних аспектів даної ділянки.

Матеріали і методи. Починаючи з 2008 року і до сьогодні, групу, яку досліджували, склали 72 пацієнти, оперовані як відкритим малоінвазивним методом, так і з 2012 року із застосуванням артроскопії. Пацієнти мали розрив РМП від малого до тотального з відривом від місць інсерції, що діагностували, використовуючи ультразвукове дослідження, а в деяких випадках магнітно-резонансну томографію в передопераційній підготовці.

Вік пацієнтів - від 28 до 80 років (середній вік 54 роки). Чоловіків було 42, жінок - 30.

61 хворий оперований за малоінвазивною відкритою методикою відновлення цілісності, реінсерції ротаційної манжети плеча з використанням анкерних фіксаторів, 11 пацієнтів оперовано з використанням анкерної фіксації і відновленням цілісності сухожильно-капсульного апарата плечового суглоба при застосуванні артроскопії.

Операційна техніка.

Малоінвазивне відкрите втручання. Використовуємо прийнятий SICOT (2005) доступ від акроміона між I та II порціями дельтоподібного м'яза розміром 4-5 см. Проводимо часткове видалення підакроміально-піддельтоподібної бурси, декомпресію підакроміального простору. Після встановлення пошкодження ротаційної манжети плеча проводимо обробку країв сухожильного розриву, відновлення ії цілісності, а за необхідності реінсерцію при використанні анкерної фіксації.
Рану ушиваємо пошарово 3 використанням активного дренування. Кінцівку тримаємо м'якою фіксуючою пов'язкою з аксіальною кутовою $15^{\circ}$ вставкою.

При використанні артроскопії. Використовуємо загальноприйняті порти доступу до плечового суглоба та ротаційної манжети плеча від 2 до 3. Проводимо часткове видалення підакроміальнопіддельтоподібної бурси, декомпресію підакроміального простору. Обов'язковим вважаємо виконання внутрішньосуглобової ревізії. При знаходженні внутрішньосуглобових пошкоджень проводимо їх усунення. Дебридмент країв розірваних сухожильних частин, відновлення цілісності ротаційної манжети плеча при використанні анкерної фіксації. Віддаємо перевагу двохрядному шву [1].

Шви на шкіру з використанням підм'язового активного дренування. Кінцівку тримаємо м'якою фіксуючою пов'язкою $з$ аксіальною кутовою $15^{\circ}$ вставкою.

3 першого дня в обох випадках після операції розпочинаємо лікувальні фізичні вправи, спрямовані на збереження пасивних рухів у плечовому суглобі, а також на збереження активних рухів у ліктьовому та кистьовому суглобах.

Термін спостереження в післяопераційному періоді склав від 1 місяця до 1 року.

У післяопераційному періоді для визначення відновлення функції верхньої кінцівки використовували шкалу Oxford shoulder score [4].

Результати досліджень та їх обговорення. Результати лікування представлено в таблицях 1 та 2.

За нашими спостереженнями, при порівнянні результатів лікування встановлено таке.

При використанні малоінвазивного відкритого відновлення цілісності РМП при малих та середніх розривах унеможливлюється ревізія суглобової порожнини, що, в свою чергу, може викликати недіагностовані, а значить, і не проліковані внутрішньосуглобові пошкодження.

Використання артроскопії дає можливість провести обстеження порожнини суглоба. За нашими спостереженнями, було виявлено розволокнення сухожилка довгої головки двоголового м'яза у 5 хворих, SLAP пошкодження в 1 хворого, ворсинчастий капсуліт в 1 хворого у поєднанні з розривом РМП. Отже, більше половини пацієнтів мали ускладнену патологію.

Втім, слід зазначити, що використання артроскопічного втручання найбільш оптимальне при малих та середніх розривах РМП та у свіжих випадках. При тотальних розривах з відривом від місця інсерції РМП та при значній ретракції сухожильних частин, застарілих пошкодженнях досить проблематично провести відновлення при використанні артроскопа. Тому в таких випадках віддаємо перевагу відкритому малоінвазивному методу. 